\title{
A general approach to incorporating spatial and temporal variation in individual-based models of fish populations with application to Atlantic mackerel
}

Article

Accepted Version

Creative Commons: Attribution-Noncommercial-No Derivative Works 4.0

Boyd, R., Roy, S., Sibly, R., Thorpe, R. and Hyder, K. (2018) A general approach to incorporating spatial and temporal variation in individual-based models of fish populations with application to Atlantic mackerel. Ecological Modelling, 382. pp. 9-17. ISSN 0304-3800 doi: https://doi.org/10.1016/j.ecolmodel.2018.04.015 Available at https://centaur.reading.ac.uk/76909/

It is advisable to refer to the publisher's version if you intend to cite from the work. See Guidance on citing.

To link to this article DOI: http://dx.doi.org/10.1016/j.ecolmodel.2018.04.015 Publisher: Elsevier

All outputs in CentAUR are protected by Intellectual Property Rights law, including copyright law. Copyright and IPR is retained by the creators or other copyright holders. Terms and conditions for use of this material are defined in the End User Agreement. 


\section{www.reading.ac.uk/centaur}

\section{CentAUR}

Central Archive at the University of Reading

Reading's research outputs online 
1 A general approach to incorporating spatial and temporal variation

2 in individual-based models of fish populations with application to

3 Atlantic mackerel

4

5 Robin Boyd ${ }^{1 *}$, Shovonlal Roy ${ }^{1,2}$, Richard Sibly ${ }^{3}$, Robert Thorpe $^{4}$, Kieran Hyder

6 1) Department of Geography and Environmental Science, University of Reading, Whiteknights, 7 Reading RG6 6AB, UK

8 2) School of Agriculture, Policy and Development, University of Reading, Whiteknights, Reading RG6 $96 \mathrm{AB}, \mathrm{UK}$

3) School of Biological Sciences, University of Reading, Whiteknights, Reading RG6 6AB, UK

4) Centre for Environment, Fisheries \& Aquaculture Science, Lowestoft Laboratory, Pakefield Road, Lowestoft NR330HT, UK

*Corresponding author; email: r.boyd@pgr.reading.ac.uk (R. Boyd); shovonlal.roy@reading.ac.uk (S.

14 Roy)

\section{Abstract}

Fish population dynamics are affected by multiple ecosystem drivers, such as food-web interactions, exploitation, density-dependence and the wider environment. While tactical management is still dominated by single-species models that do not explicitly account for these drivers, more holistic ecosystem models are used in strategic management. One way forward in this regard is with individual-based models (IBMs), which provide a single framework in which these drivers can be represented explicitly. We present a generic marine fish IBM that incorporates spatial and temporal variation in food availability, temperature and exploitation. Key features of the model are that it (1) includes realistic energy budgets; (2) includes the full life cycle of fish; (3) is spatially-explicit and (4) incorporates satellite remote-sensing data to represent the environmental drivers. The rates at which individuals acquire and use energy depend on local food availability and temperature. Their state variables, including life stage, size and energy reserves, are updated daily, from which population structure and dynamics emerge. To demonstrate the use of the model we calibrate it for mackerel (Scomber scombrus) in the North East Atlantic. Most parameters are taken from the literature, except the background early mortality rate and the strength predator density dependence, which were estimated by fitting the model to data using Approximate Bayesian Computation. The calibrated model successfully matches the available data on mackerel population dynamics and structure. We demonstrate the use of the model for management purposes by simulating the population effects of opening and closing a sector of the North Sea to mackerel fishing. Our model uses basic principles of behavioural and physiological ecology to establish how spatial and temporal variations in ecosystem drivers affect the individuals in the population. Population dynamics and structure are calculated from the collective effects on individuals. Application to a test case shows the method can fit available data well. Individual-based approaches such as this study have potential for use in strategic management because they can account for spatial structuring, food-web interactions, density dependence, and environmental drivers within a single framework.

Keywords: Atlantic mackerel, bioenergetics, energy-budget, individual-based model, spatially-explicit 
43

44

45

46

47

48

49

50

51

52

53

54

55

56

57

58

59

60

61

62

63

64

65

66

67

68

69

70

71

72

\section{Introduction}

The aim of fish stock assessment is to enable management to maximise the long-term yield from a fishery, without doing irreversible damage to the stock or wider environment (Hilborn and Walters, 1992). This traditionally involved estimating one or more reference points, such as spawning stock biomass or the rate of exploitation, by fitting mathematical models to the available data on the fishery and its population dynamics (Cadrin and Dicky-Collas, 2013). Increasingly, regulatory bodies worldwide are adopting an ecosystem-based approach to fisheries management (Garcia and Cochrane, 2005). This stems from the realisation that a stock's biological reference points will depend on other components of the ecosystem, including food-web interactions, the associated density-dependent processes (e.g. growth), and the wider environment (Skern-Mauritzen et al., 2015). Accordingly, a variety of more holistic models have been developed that can account for these drivers. Examples include age/size structured models such as OSMOSE (Shin and Cury, 2004, 2001) and LeMANS (Hall et al., 2006); food-web models such as Ecopath with Ecosim (Polovina, 1984); and multispecies oceanographic models such as Atlantis (Fulton et al., 2004). These "ecosystem" models have been applied to strategic management questions, such as testing the response of fish populations or communities to different fishing scenarios (e.g. Kaplan et al., 2013; Thorpe et al., 2016; Travers et al., 2010).

The population effects of ecosystem drivers, including the wider environment, food-web interactions and associated density-dependent processes, often arise from their effects on the constituent individuals (Ward et al., 2016). Modelling these individual-level effects requires inclusion of processes such as adaptive traits (e.g. physiology), variation among individuals and local interactions, which traditional population models cannot easily accommodate (DeAngelis and Grimm, 2014). One way forward in this regard is with individual-based models (IBMs, also called agent-based models) (Grimm et al., 2005). In IBMs the lives of individual animals are simulated as they interact with each other and their environment (DeAngelis and Grimm, 2014). Individuals have a unique set of state variables (e.g. size and location), while the landscapes are often dynamic and characterised by environmental drivers (McLane et al., 2011; van der Vaart et al., 2016). Individual's state variables are updated when they interact with each other and their environment, and it is from simulation of all the individuals that population dynamics and structure emerge. In this way, IBMs can incorporate food-web interactions, density dependence and environmental drivers, and predict the fate of populations in defined spatially-explicit landscapes that vary over time.

IBMs have long been applied to fish populations. A major area of interest has been the merger of IBMs with bioenergetics as a way to model the response of populations to their physical and biological environment (Lett et al., 2009). Initial focus was on the food and temperature dependence of growth and survival in young-of-the-year fish (e.g. Bartsch and Coombs, 2004; Rose et al., 1999; Scheffer et al., 1995). Since then, increasing computer power has permitted the development of multi-generational bioenergetics IBMs that include the full life cycle (e.g. Politikos et al., 2015). It is these IBMs that can address strategic management questions, including the effects of environmental drivers on migrations and reproductive output, and the effects of fishing scenarios (Lett et al., 2009). Because of their complex nature, existing full life cycle bioenergetics IBMs are typically speciesspecific (e.g. Pethybridge et al., 2013; Politikos et al., 2015). Yet, there are many similarities among species in terms of their energy budgets and the way they scale with body size and temperature. The same functional forms often well describe the rates of energy uptake and its expenditure on vital processes such as maintenance, growth and reproduction (Clarke and Johnston, 1999; Peters, 1983; Sibly et al., 2013), raising the hope that a minimum generic bioenergetics model can be developed.

We present a generic marine fish IBM built on basic principles of behavioural and physiological ecology (Sibly et al. 2013; van der Vaart et al. 2016). Our model is spatially-explicit, includes a realistic energy budget and the full fish life cycle. The model landscape consists of dynamic maps of two variables derived from satellite remote-sensing (RS): sea surface temperature (SST), and chlorophyll concentration, a proxy for phytoplankton biomass, which we use to represent baseline 
food availability. Individuals respond to their local food availability and SST according to their energy budgets. To demonstrate the use of the model we calibrate it for the western component of the North East Atlantic mackerel (S. scombrus) stock. We chose this particular stock to demonstrate the potential of the IBM approach because (1) it is well-defined and subject to a specific management regime; (2) density dependence within the stock is strong, both in terms of passive competition for food (Jansen and Burns, 2015) and cannibalism (Fortier and Villeneuve, 1996); (3) its population dynamics are sensitive to environmental drivers (e.g. recruitment) (Borja et al., 2002; Villamor et al., 2011); (4) it is widely-distributed and has distinct spawning, feeding, overwintering and nursery areas (Petitgas et al., 2010), meaning spatial variation in exploitation and environmental drivers are important; (5) its wide distribution raises important management questions that cut across international jurisdictions; and (6) there is much field data available on its population dynamics and structure, and experimental data for parameterizing the energy budget. We report that the model fits data on mackerel population dynamics and structure well, and demonstrate how it may be applied by simulating the consequences of hypothetical spatial management scenarios.

\section{Methodology}

\subsection{Model overview}

In broad terms, the model landscape consists of dynamic maps of sea surface temperature SST and food availability (Fig. 1). Fish are grouped into super-individuals (hereafter termed individuals), which comprise a number of individuals with identical variables (Scheffer et al., 1995). Individuals move around the landscape according to their life cycles (e.g. to spawn or feed) (Fig. 1). Each individual has an energy budget which determines how its characteristics (e.g. body size, life stage, energy reserves) change in response to local food availability (including smaller fish) and SST. Fishing pressure at different locations determines the rate of mortality from exploitation. The abundance represented by each super-individual when it enters the model at the egg stage is determined by the amount of energy the spawning stock has put into egg production. Abundance reduces as mortality is applied throughout life. Population measures are calculated as the sum of the characteristics of all the individuals including their abundances. The model is implemented in Netlogo 5.3.1 (Wilensky 1999). 


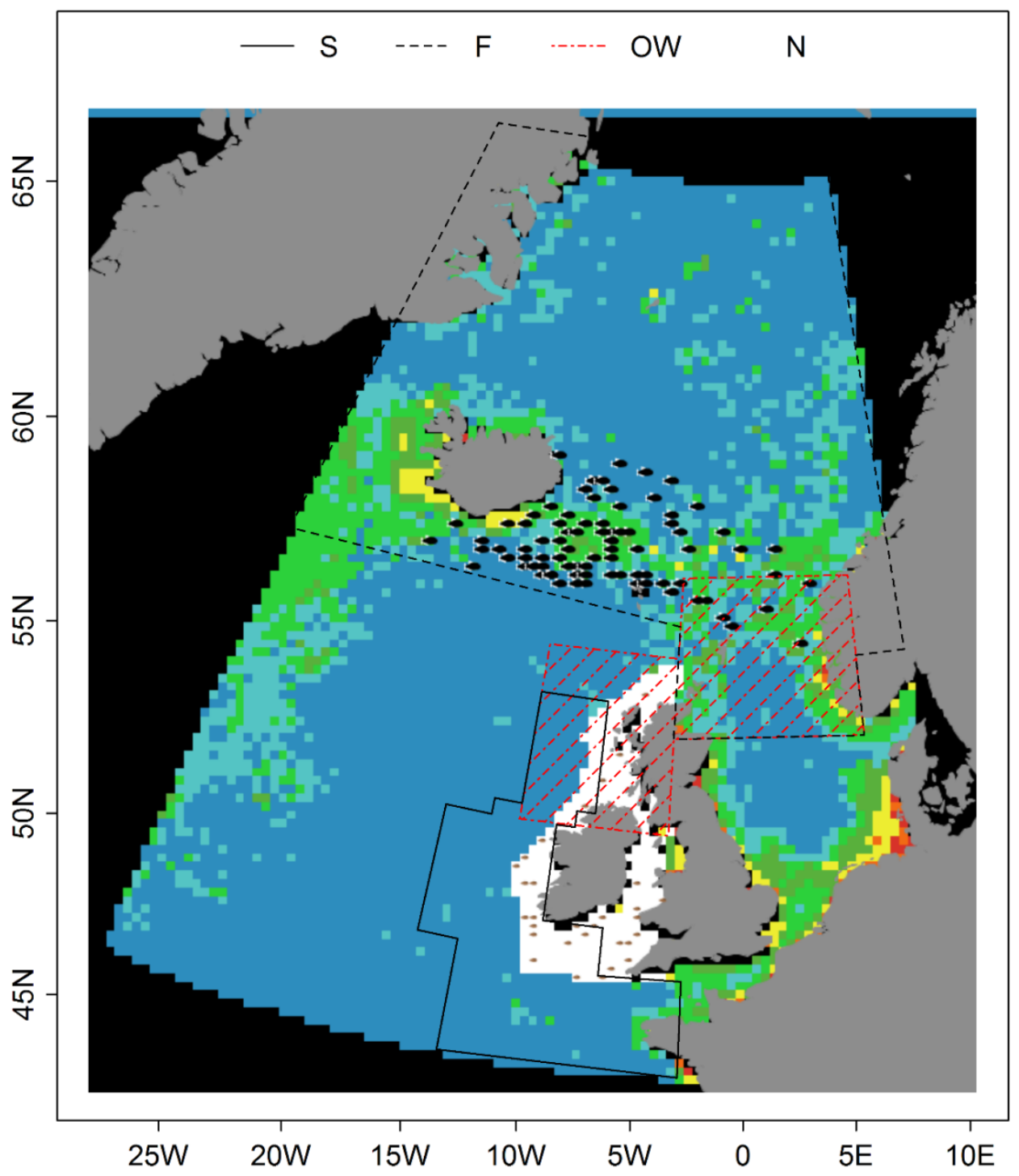

122 Figure 1. An example model interface showing potential spawning $S$ (solid line), feeding $F$ (dashed line), overwintering OW (dotted red line) and nursery (white filled) areas (referred to later). Black fish are adults, brown fish are juveniles and the colour of the landscape corresponds to phytoplankton biomass. Phytoplankton biomass and SST are obtained from satellite remote sensing, and the landscape is updated at regular intervals. This example is taken from the case study of Atlantic mackerel described later.

128 In the following we describe the generic model and its application to Atlantic mackerel. For a full technical specification see the "TRAnsparent and Comprehensive model Evaludation" (TRACE) document (Augusiak et al., 2014; Grimm et al., 2014; Schmolke et al., 2010) in the supplementary material. In section 2 of the TRACE we provide a model description in the standard Overview, Design Concepts and Details (ODD) format (Grimm et al., 2010, 2006). 
133

134

135

136

137

138

139

140

141

142

143

144

145

146

147

148

149

150

151

152

153

154

\subsection{Generic model description}

\subsection{State variables and scales}

The model landscape comprises a two-dimensional grid of patches of sea surface (Fig. 1). Each patch is characterised by its baseline food density (phytoplankton biomass), sea surface temperature (SST), latitude, longitude, area type (e.g. spawning, feeding, transitory), fishing division (see ICES.dk), whether or not it is open to fishing, and depth. Fish populations are represented by a number of individuals, characterised by age, gender, life stage (egg, yolk-sac larvae, larvae, juvenile or adult), length, mass (structural, lipid and gonad) and abundance. The model proceeds in discrete daily timesteps.

\subsection{Model schedule}

Full details of the model processes are given in section 2.23 (Sub-models). In each daily time-step, phytoplankton, SST and fishing mortality F are updated first. Individuals begin their daily schedule by calculating their mortality (see Mortality). Next, they calculate their swimming speed (Swimming speed) and move (Movement). Individuals then calculate their energy budgets, except for reproduction (Energy budget). Energy is allocated to different components of the energy budget, depending on life stage and time of year (Fig. 2). Most state variables have been updated at this point. If certain conditions are met, individuals proceed to the subsequent life stage (Transformation). If in the spawning period, adults then calculate the costs of reproduction, allocate energy to reproduction (Energy budget), and spawn. This involves the introduction of new individuals (eggs) into the model in each year. Eggs then calculate their development (Egg development) and all individuals age by one day. At the end of each time-step population measures are recorded. The order in which individuals or patches carry out a given process is random. 


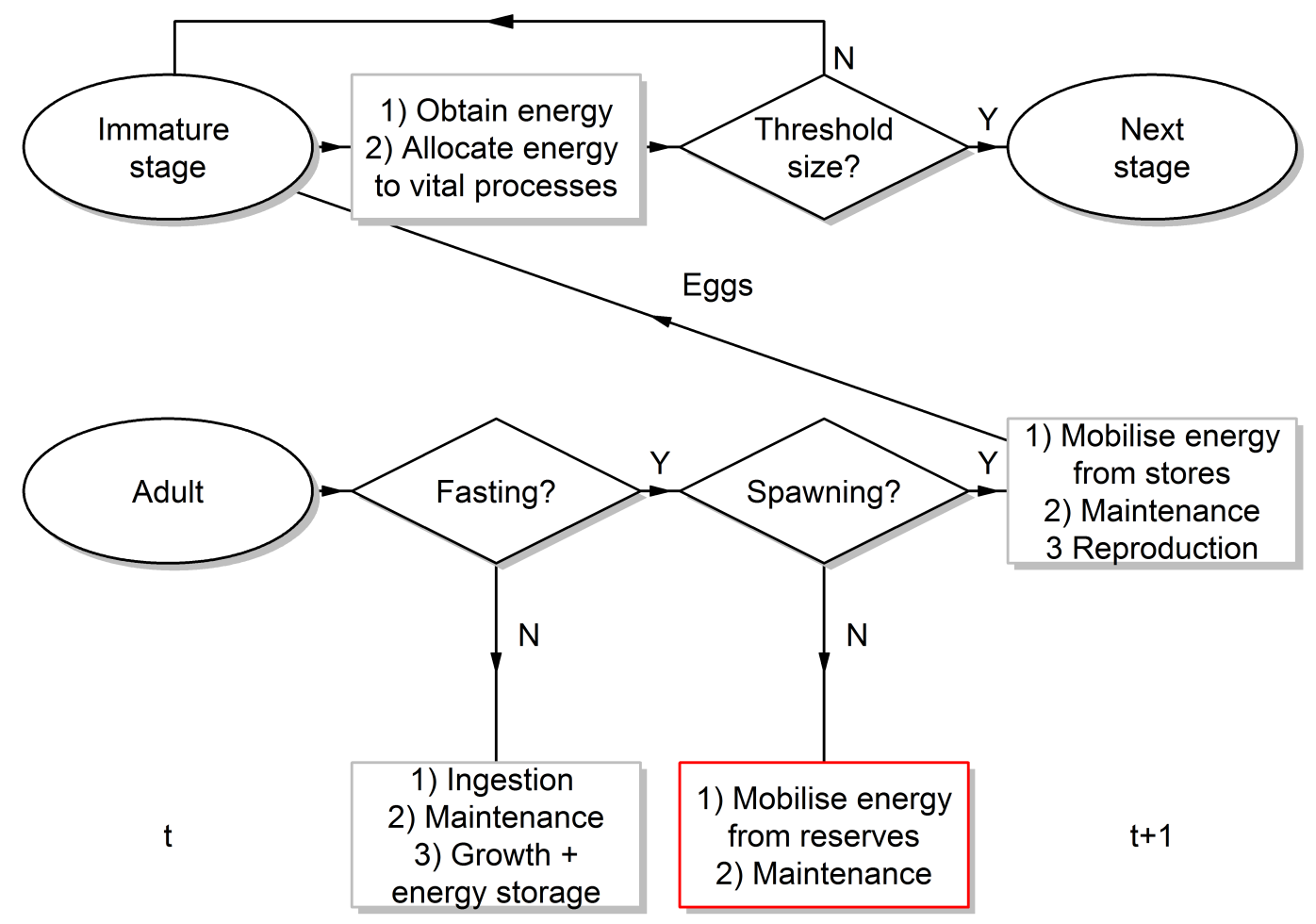

Figure 2. Conceptual model showing the processes that individuals implement between time $t$ and $t+1$. Individuals start as eggs, then become yolk-sac larvae at the end of their development period. They then grow to become larvae, juveniles and finally adults when reaching size thresholds. Juveniles can only become adults at a certain time of year. The first process in each day is obtaining energy, generally by ingestion, although yolk-sac larvae absorb energy from the yolk-sac. Obtained energy is allocated first to maintenance, with the remainder going equally to growth and energy reserves (except yolk-sac larvae which do not store energy, and larvae which prioritise growth). Red boxes indicate an effect of SST, and grey boxes an effect of SST and food availability.

\subsection{Sub-models}

In this section we provide details of the model processes. See TRACE section 2 for a full list of parameters; values of most parameters are taken from the literature.

Swimming speed: The speed at which individuals can sustainably swim $\mathrm{S}_{\mathrm{a}}$ is given as a function of their body length $L$ and their caudal fin aspect ratio $A_{r}$ (Sambilay Jr, 1990). From this their daily search radius is calculated.

171 Movement: Movement patterns are species-specific so we do not provide a generic model.

Energy budget: The following sub-models describe the energy budgets of larvae, juveniles and adults (for overview see Fig. 2) in terms of individual physiology. We assume the yolk-sac provides sufficient energy for eggs and yolk-sac larvae to achieve maintenance and maximal growth/development rates. 
Temperature dependence: We use the exponential Arrhenius function to describe the effects of temperature SST on rates of energy uptake and allocation. This has the form $e^{-E_{a} / K S S T}$, where $\mathrm{E}_{\mathrm{a}}$ is the activation energy and $\mathrm{K}$ is Boltzmann's constant.

Food: Other individuals within the focal individual's search radius and $\geq 3.5$ times smaller (see Shin \& Cury 2001) constitute potential prey. If multiple prey are available then one is chosen at random to be eaten. Food density $\left(\mathrm{g} \mathrm{m}^{-2}\right)$ is calculated from the mass of the chosen prey and the predator's search area. The energy content of prey depends on how much lipid it has stored. When individuals do not overlap with potential fish prey they instead eat phytoplankton, which has an energy content $E_{p}$. Although most fish do not feed directly on phytoplankton, we use it as a proxy for baseline food availability because it provides a synoptic view of the base of the food chain.

Ingestion and energy uptake: Ingestion rate IR is given as a function of predator density $\mathrm{D}$, food density X, SST and body surface area (body mass ${ }^{2 / 3}$ ) (Kooijman and Metz, 1983), according to the Beddington-DeAngelis functional response (Beddington, 1975; DeAngelis et al., 1975). IR is converted from $\mathrm{g} \mathrm{day}{ }^{-1}$ to $\mathrm{kJ} \mathrm{day}^{-1} \mathrm{using}$ the energy content of food $\left(\mathrm{kJ} \mathrm{g}^{-1}\right)$. A proportion of ingested energy, an assimilation efficiency $A_{e}$, becomes available for allocation to the processes in Fig. 2.

Maintenance: Standard metabolic rate SMR, the level below which an individual cannot survive (Fry, 1971), is used as a baseline measure of maintenance. SMR scales with body mass M and with SST. For many species migrations represent a significant energy cost. We incorporate this by substituting SMR for an elevated active metabolic rate AMR $\left(\mathrm{KJ} \mathrm{day}^{-1}\right)$ when migrating, given as a function of $M$, SST and swimming speed.

Growth: Fish growth typically has a different form and rate in the first growing season than in later life. We use the sigmoid Gompertz function to describe growth rate in optimal conditions as a function of L and SST in the first growing season (Gluyas-Millan et al., 1998; Goldman, 2005; Sirnard et al., 1992). After reaching an age threshold $\mathrm{G}_{\text {thresh, }}$ growth switches to von Bertalanffy form (von Bertalanffy, 1938), again as a function of $L$ and SST (Goldman, 2005). We assume that fish species which exhibit fasting periods grow only when feeding. Daily growth increment $\Delta \mathrm{L}(\mathrm{cm})$ is converted to the difference in structural mass $\Delta \mathrm{M}(\mathrm{g})$ using a standard allometric relationship (see FishBase weight-length table at www.fishbase.org and TRACE section 3). We define structural mass as body mass minus lipid stores and gonads. Growth costs are calculated using $\Delta M\left(E_{c}+E_{s}\right)$, where $E_{c}$ is the energy content of flesh $(\mathrm{kJ})$ and $E_{S}$ is the energy costs of synthesising flesh $\left(\mathrm{kJ} \mathrm{g}^{-1}\right)$. If insufficient energy is available to support maximum growth, the growth rate is reduced accordingly.

Reproduction: The energy cost of producing a maximum-sized batch of eggs $B_{\max }\left(\mathrm{kJ} \mathrm{day}^{-1}\right)$ is modelled as $B_{\max }=F_{p} M_{0}\left(E_{c}+E_{s}\right) / N_{b}$, where $F_{p}$ is potential fecundity, $M_{0}$ is egg mass, $E_{c}$ is the energy content of flesh, $E_{s}$ is the cost of synthesising tissue and $N_{b}$ is the number of batches produced. $F_{p}$ is often related to body size (see FishBase fecundity table). For total spawners (i.e. $N_{b}=1$ ) $B_{\max }$ equals the maximum total energy costs of spawning. For batch spawners energy is allocated to each batch over the inter-batch intervals. If less energy than $B_{\max }$ is available, batch size is reduced accordingly. We define gonad mass as equal to the mass of the eggs produced in a batch. This increases as energy is allocated to a batch, then is reset to zero when that batch is spawned. The egg production of all females is divided equally among $n$ new individuals each year. We assume that male and female investment in reproduction is equal.

Energy reserves: Fish typically store energy as lipid (Martin et al., 2017). We propose that when feeding individuals can store lipid up to their maximum possible energy reserves $E_{\max }$. The energy costs of synthesising lipid is accounted for when assimilated energy is converted to energy stores. The mass of stored lipid and, for adults, the gonads are added to structural mass to get total mass $\mathrm{M}$. 
Egg development: Egg development time $D_{\mathrm{e}}$ typically depends on temperature (Pepin, 1991) and can be modelled with an Arrhenius function.

Transformation: The transformations of eggs into yolk-sac larvae at length $L_{\text {hatch, }}$ yolk-sac larvae into larvae, larvae into juveniles and juveniles into adults (sexual maturation) are defined using body length thresholds.

Mortality: The ways in which the number of individuals, or their sub-individuals, decrease are as follows. Starvation: If an individual's total mass reduces to its structural mass it dies. Explicit predation: Individuals die from the explicit portion of predation at rate $M_{\text {pred, }}$ given as ingestion rate of the predator $\left(\mathrm{g} \mathrm{day}^{-1}\right)$ / mass of prey (g). Background mortality: Eggs and larvae are susceptible to background mortality $M_{\text {back }}$ at (typically very high) rate $M_{e}$. Juvenile susceptibility at length $L$ is given by $M_{\text {back }}=M_{a}\left(L_{\text {mat }} / L\right)$, where $M_{a}$ is a constant equal to adult mortality susceptibility $\left(\right.$ day $\left.^{-1}\right)$ and $L_{\text {mat }}$ is the threshold length at which juveniles can sexually mature (Brodziak et al., 2011). Because $M_{\text {back }}$ decreases with life stage or $L$, cumulative mortality depends on growth. Fishing mortality: Fishing mortality rates $F\left(\right.$ day $\left.^{-1}\right)$ at-age vary between years and are applied each day. $F$ is set to 0 in areas that are closed to fishing (see Hypothetical management scenarios in section 2.3). Individuals with abundance $<1$ are removed from the model.

\subsection{Application of the model to Atlantic mackerel}

In the following we describe the model's application to S. scombrus in the North East Atlantic.

Model landscape: The model landscape spans from $-30^{\circ} \mathrm{W}$ to $10^{\circ} \mathrm{E}$ and from $47^{\circ}$ to $75^{\circ} \mathrm{N}$. Landscape patches represent $30 \times 30 \mathrm{~km}$. Potential spawning, feeding, overwintering and nursery areas are shown in Fig. 1. The spawning area corresponds to the priority areas for sampling of $S$. scombrus eggs in the mackerel egg survey (MEGS, ICES, 2014b) in which $10^{\circ} \mathrm{C}<\mathrm{SST}<12^{\circ} \mathrm{C}$ (Sette, 1943). The feeding area comprises all patches $\geq 62^{\circ}$ north and the northern North Sea (division 4a), above the lower temperature limit $\mathrm{SST}_{\lim }\left(>7^{\circ} \mathrm{C}\right.$ ) (Nottestad et al., 2016). The overwintering area is assumed to be ICES divisions $6 a$ (west of Scotland) and $4 a$ (northern North Sea). The nursery area includes all patches that are $\leq 200 \mathrm{~m}$ deep (Jansen et al., 2014) to the west of the British Isles $\left(<4^{\circ}\right.$ west).

Life cycle and spatial patterns: In broad terms, eggs and larvae drift from the spawning towards nursery areas at a fixed rate; juveniles move locally in the nursery areas until maturing as adults; and adults cycle between spawning, feeding and overwintering areas. Migration triggers imposed, but arrival times in destination areas depend on an individual's swimming speed. Adults fast from November until after spawning the following year. See TRACE section 2 for full details.

Data: Input data includes fishing mortality $\mathrm{F}\left(\mathrm{day}^{-1}\right)$, phytoplankton biomass $\left(\mathrm{g} \mathrm{m}^{-2}\right)$, SST (kelvins) and bathymetry. $F$ comes from the stock assessment as age-specific rates that vary annually. Phytoplankton biomass and SST were derived from data from the MODIS sensor on NASA's Aqua satellite (NASA OBPG, 2017a, 2017b). Eight-day composites are used at a spatial resolution of $30 \times 30$ $\mathrm{km}$. Bathymetric data was obtained from the British Oceanographic Data Centre. See TRACE section 3 for details of data processing.

The model was calibrated with indices of spawning stock biomass (SSB) (Nøttestad et al., 2016, 2015), total annual egg production (TEP) (ICES, 2017) and recruitment (Jansen et al., 2014).

Data on population structure used to validate the model included maturity ogives (from stockassessment.org), average weight-at-age (Nøttestad et al., 2016), monthly variation in the weight of $36 \mathrm{~cm}$ fish (Olafsdottir et al., 2016), and age (Nøttestad et al., 2016) and length distributions (ICES, 2017). Details of all data are given in section 2 of the TRACE. 
Initialization: The population size and structure on January $1^{\text {st }} 2007$ was approximated using estimates of spawning (SSB) and total stock biomass (TSB), and length and age compositions from commercial catch samples (ICES, 2008) and bottom-trawl surveys (ICES, 2017). This population is then apportioned into 150 super-individuals. Each simulation begins with a 20 -year spin up using 2007 data in an annual loop. See TRACE section 2 for full details.

Model simulations: The model simulates the mackerel population from Jan $1^{\text {st }} 2007$ to December $31^{\text {st }}$ 2015. We represent the population with 150 individuals, representing a compromise between computational demands and realism. See TRACE section 8 for the sensitivity of model outputs and execution speed to changes in the number of individuals. Simulations are forced by $F$, phytoplankton biomass and SST. F at-age is updated each year and applied each day. SST and phytoplankton biomass are updated every eight days.

Outputs that are recorded annually include: SSB, the average weight at age, adult age distribution on the feeding grounds, TEP, recruitment (age 0 ), maturity ogives and length distributions at two times of the year. The average weight of $36 \mathrm{~cm}$ individuals is also recorded monthly. All outputs are recorded to match the times at which corresponding data was collected (full details in TRACE section 2).

Local sensitivity analysis: The sensitivities of predicted SSB, recruitment and egg production are presented as the change in output relative to $10 \%$ change in the energy budget parameters in Table 1. Changes in outputs were averaged over an increase and decrease in the parameter, and over five simulations. While one parameter was tested all others were kept at their baseline values (TRACE section 2). See TRACE section 7 for a full list of parameters.

Model calibration: We calibrated the parameters background early mortality $\mathrm{M}_{\mathrm{e}}$ and the strength of predator density dependence $c$ using rejection approximate Bayesian computation (ABC), generally following the methodology of van der Vaart et al. (2015). This involved running the model 4500 times, drawing $M_{e}$ and $c$ from uniform prior distributions and "accepting" the values that minimised the sum of the squared differences between the model outputs and the data. See TRACE section 3 for full details.

Hypothetical management scenarios: To demonstrate the model's potential to test spatial management strategies, we implemented two hypothetical scenarios: (1) closing the northern North Sea (ICES division 4a, see Fig. 5) to mackerel fishing all year; and (2) opening division 4a all year. In reality (and all other simulations) division 4 a is closed from $15^{\text {th }}$ February to $1^{\text {st }}$ September (ICES, 2014b). The closure of division 4a is designed to protect the smaller North Sea component of Atlantic mackerel which are found in the area (ICES, 2014b).

\section{Results}

\subsection{Local sensitivity analysis}

The sensitivities of SSB, recruitment and egg production to key model parameters are shown in Table 1. SSB is the most robust variable (relative sensitivities $<1$ generally), and recruitment the least. In particular, recruitment is highly sensitive to the background early mortality rate $M_{e}$ and the Gompertz growth constant $k_{1}$. This is expected because $M_{e}$ is very high and individuals are only susceptible to it until reaching a size threshold $(3 \mathrm{~cm})$, the duration of which is affected by $k_{1}$. Hence these parameters jointly determine cumulative early mortality and recruitment.

Table 1. Sensitivities of SSB, recruitment and TEP to $10 \%$ changes in parameter values, presented as the change in output relative to change in parameter, averaged over ten simulations, and over an increase and decrease in the parameter value. Only the energy budget parameters are shown, along with their standard deviations 


\begin{tabular}{llll}
\hline & \multicolumn{3}{c}{ Relative sensitivity of output } \\
\hline Parameter & SSB & Recruitment & TEP \\
Normalizing constant for AMR $\left(\mathrm{A}_{0}\right)$ & $0.14 \pm 0.07$ & $1.67 \pm 1.25$ & $1.31 \pm 0.64$ \\
Assimilation efficiency $\left(\mathrm{A}_{\mathrm{e}}\right)$ & $0.38 \pm 0.06$ & $1.38 \pm 0.48$ & $0.95 \pm 0.41$ \\
Strength of predator density & $0.14 \pm 0.05$ & $1.58 \pm 0.90$ & $1.46 \pm 1.07$ \\
dependence $(\mathrm{c})$ & & & \\
Maximum consumption rate $\left(\mathrm{C}_{\mathrm{max}}\right)$ & $0.35 \pm 0.08$ & $1.19 \pm 0.50$ & $1.31 \pm 0.71$ \\
Activation energy $\left(\mathrm{E}_{\mathrm{a}}\right)$ & $0.24 \pm 0.10$ & $3.01 \pm 0.82$ & $1.38 \pm 0.72$ \\
Half saturation constant $(\mathrm{h})$ & $0.22 \pm 0.07$ & $1.68 \pm 1.87$ & $1.53 \pm 0.81$ \\
Bertalanffy growth constant $(\mathrm{k})$ & $0.17 \pm 0.09$ & $1.72 \pm 1.30$ & $1.06 \pm 0.51$ \\
Gompertz growth constant $\left(\mathrm{k}_{1}\right)$ & $0.18 \pm 0.10$ & $7.12 \pm 1.66$ & $1.68 \pm 0.68$ \\
Maximum length after the first & $0.10 \pm 0.06$ & $2.37 \pm 1.28$ & $1.38 \pm 0.76$ \\
growing season $\left(\mathrm{L}_{1}\right)$ & & & \\
Asymptotic length $\left(\mathrm{L}_{\infty}\right)$ & $0.74 \pm 0.05$ & $1.44 \pm 1.04$ & $2.0 \pm 0.84$ \\
Background adult mortality $\left(\mathrm{M}_{\mathrm{a}}\right)$ & $0.17 \pm 0.05$ & $1.65 \pm 0.98$ & $1.45 \pm 1.10$ \\
Background early mortality $\left(\mathrm{M}_{\mathrm{e}}\right)$ & $0.11 \pm 0.07$ & $9.0 \pm 1.90$ & $1.77 \pm 0.98$ \\
Normalizing constant for SMR $\left(\mathrm{S}_{0}\right)$ & $0.15 \pm 0.11$ & $1.46 \pm 0.94$ & $1.58 \pm 0.86$ \\
\hline
\end{tabular}

310

\subsection{Model calibration}

$M_{e}$ and $c$ were calibrated from indices of SSB, TEP and recruitment using ABC. The values that resulted in the best fits were $M_{e}=0.325$ day $^{-1}$ with credible interval $0.292-0.327$, and $c=0.98 \times 10^{-12}$ with credible interval $1.18 \times 10^{-13}-4.8610^{-12}$. These were obtained from the best-fitting $1 \%$ of the 4500 simulations. The posterior credible intervals were significantly narrower than those of the priors (Levene's test, $p<0.01$ ), meaning the data had leverage over their values. See TRACE section 3 for cross validation and a comparison of the prior and posterior distributions.

To determine the goodness of fit between the model predictions and the survey indices of population dynamics used for calibration, we used the coefficient of determination $\left(R^{2}\right)$, i.e. the proportion of the variance explained. The model predictions and survey indices for SSB, TEP and recruitment are shown in Figs. $3 a, b$ and c, respectively. Overall the fits are good, as indicated by $R^{2}$ values of $0.70,0.97$ and 0.80 , respectively. The data used for calibration are relative indices, but see TRACE section 8 for a comparison with the stock assessment's estimates of SSB and recruitment on an absolute scale. 
a) SSB

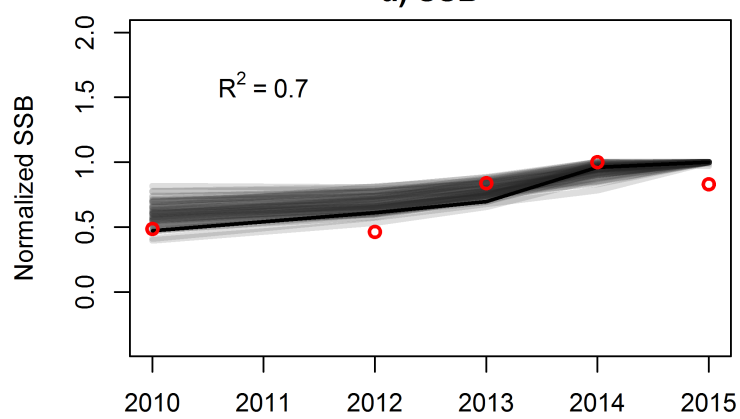

c) recruitment

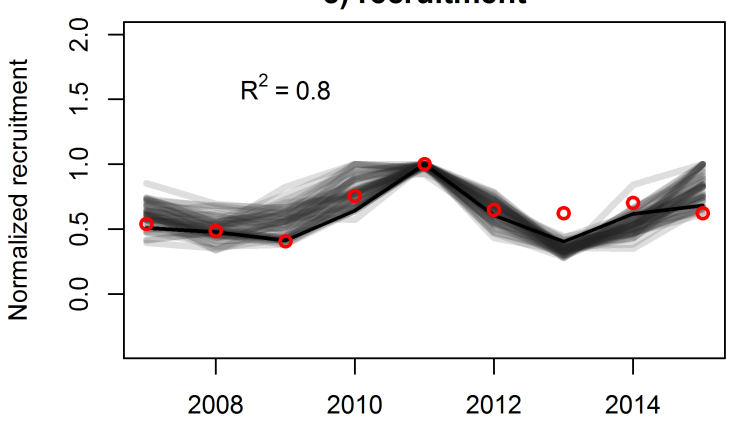

b) egg production

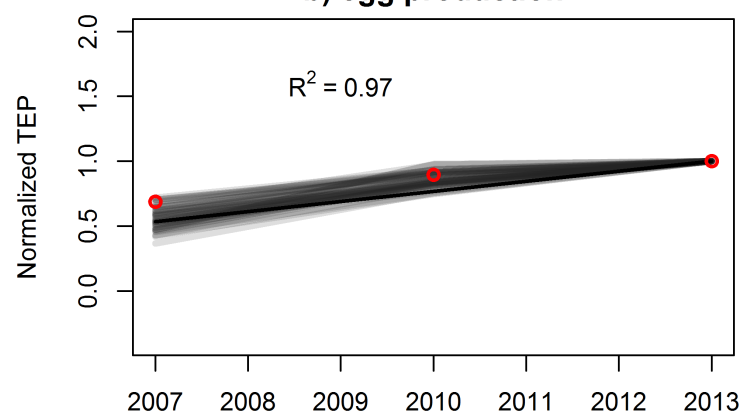

Figure 3. Fits of the best-fitting $1 \%$ of simulations from $A B C$ (transparent lines with the single bestfitting simulation in black) to the survey indices (red circles) of: a) SSB from the International Ecosystem Survey in the Nordic Seas (IESSNS) on the feeding grounds in July-August of 2010 and 2012 to 2015; b) TEP from MEGS in 2007, 2010 and 2013; and c) recruitment (see Jansen et al., 2014). Only outputs from the years with data are presented. Outputs and data were each normalized by dividing by their maximum value. $\mathrm{R}^{2}$ values from the best-fitting simulations are presented on the plots

\subsection{Model validation}

To validate the model, we compared the predicted population structure to data. Fig. 4 shows the model predictions and data averaged over 2007 to 2015, except Fig. 4d where the data is averaged over 1984 to 2013. The proportion of each age class that is sexually mature in February is shown in Fig. 4a. The model and data agree that most individuals reach sexual maturity when aged two, although there is more variability in the age at maturity in the data. Fig $4 \mathrm{~b}$ shows the age distribution on the feeding grounds in summer. The model predicts an absence of one or two-year-olds. The data suggests that there are few one year olds, but that two year olds are among the most abundant age groups. From the age of three both the model and data show a characteristic type 3 survivorship curve, i.e. declining abundance at age. Fig. $4 \mathrm{c}$ shows the mean weight at age three to ten in summer. The model matches the data well, albeit with a slight overprediction in older individuals. Fig. $4 \mathrm{~d}$ shows the average weight of $36 \mathrm{~cm}$ mackerel (approximately 5 years old) from April to September. The model and data show a similar increase in weight-at-length each month. Figs. $4 \mathrm{e}$ and $\mathrm{f}$ show length distribution in ICES division 6a (West of Scotland) in quarters 1 (Q1) and 4 (Q4). The distributions have multiple modes, each representing a cohort. Predicted modal length of ages zero to two are all matched to within one $\mathrm{cm}$, other than age two in Q1. However, within each cohort predicted length has considerably less variability than the data. Overall the model matches the observed population structure well, which supports our representation of the energy budget. 


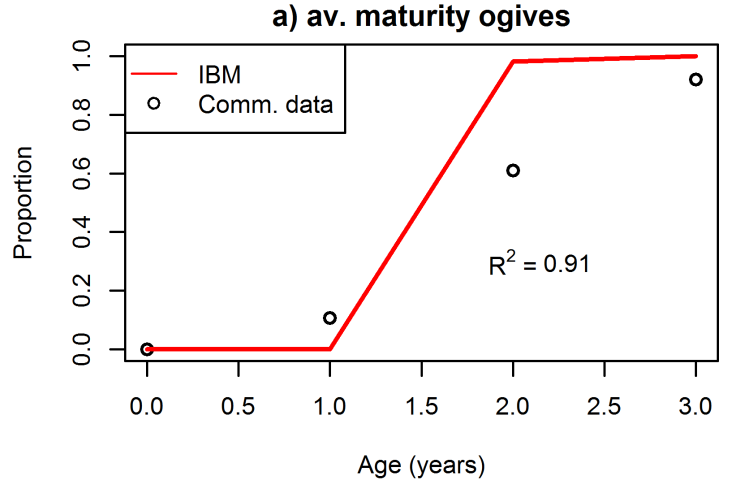

c) av. summer weight-at-age

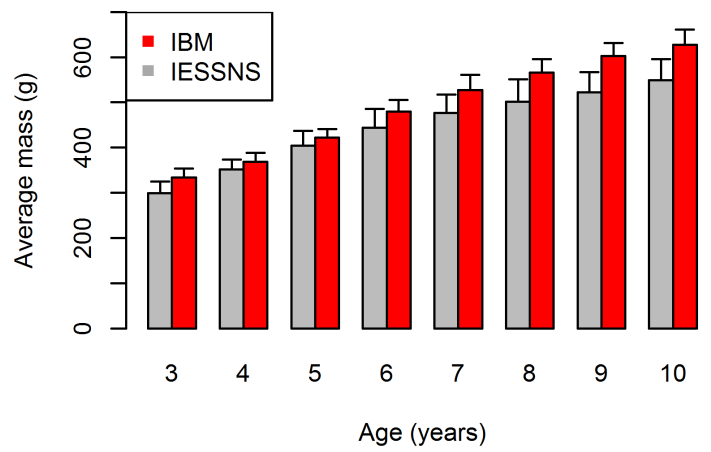

e) av. Q1 length distribution

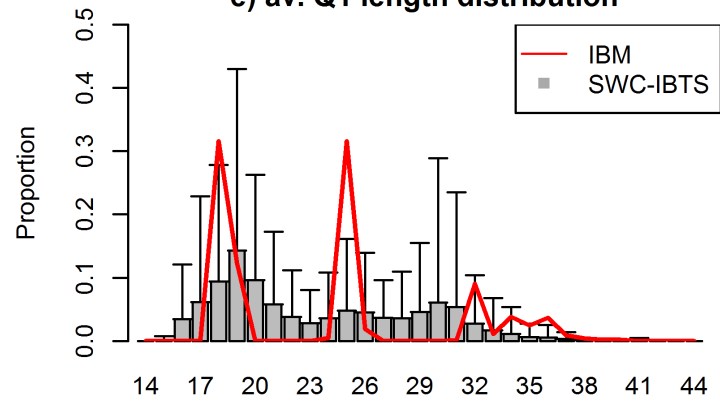

Length class $(\mathrm{cm})$ b) av. summer age distribution

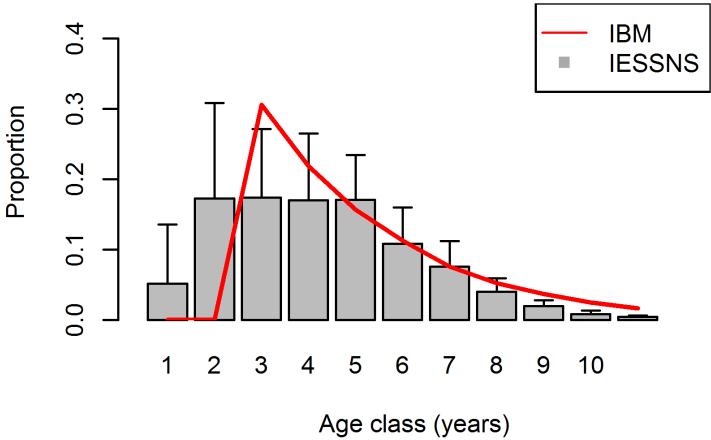

d) av. weight of $36 \mathrm{~cm}$ fish

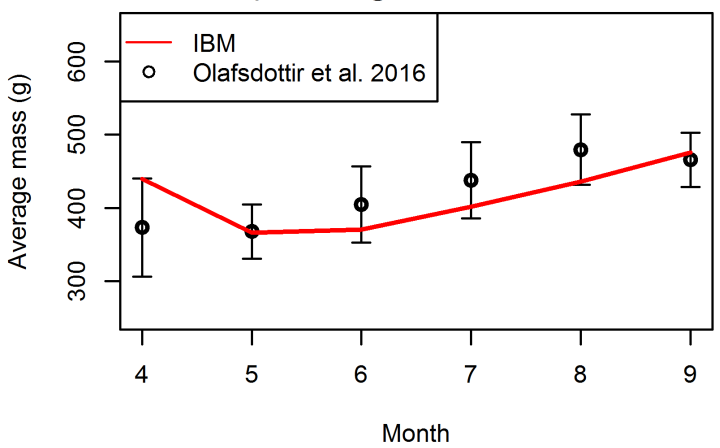

f) av. Q4 length distribution

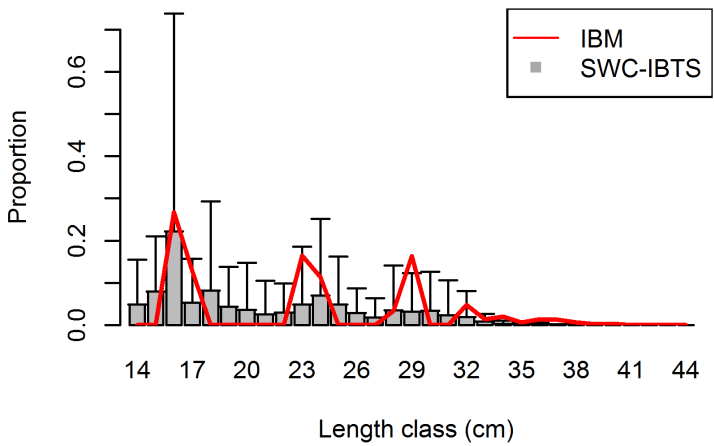

Figure 4. Comparisons of the IBM predictions with various data averaged over 2007 to 2015 on: a) proportion mature at age from sampling of commercial catches in quarter 1 ; b) the age distribution on the feeding grounds in July from the International Ecosystem Survey in the Nordic Seas (IESSNS); c) the average weight-at-age from the IESSNS in July; d) monthly variation in the average weight of $36 \mathrm{~cm}$ fish (Olafsdottir et al., 2016); and e) and f) length distributions from the Scottish West Coast International Bottom-Trawl Survey (SWC-IBTS) in quarters 1 and 4 respectively. Dots show mean values and whiskers the standard deviation

\subsection{Hypothetical management scenarios}

To demonstrate how the model may be used in a management context, we simulated two hypothetical scenarios, in which ICES division 4a was (1) closed year-round and (2) open year-round, in addition to the baseline (closed $15^{\text {th }}$ February to $1^{\text {st }}$ September). Figs. $5 \mathrm{a}-\mathrm{c}$ show how SSB, recruitment and the length distribution of large individuals $(\geq 33 \mathrm{~cm})$ on February $1^{\text {st }}$ differ under each scenario. Fig. $5 d$ shows the proportion of adults in division 4 a averaged over each month of the year for reference. SSB and recruitment are highest, and length distribution is more skewed towards large individuals, when division $4 \mathrm{a}$ is closed, followed by the baseline then open. These results are expected but highlight the model's ability to test the consequences of spatial management scenarios. 
a) average SSB

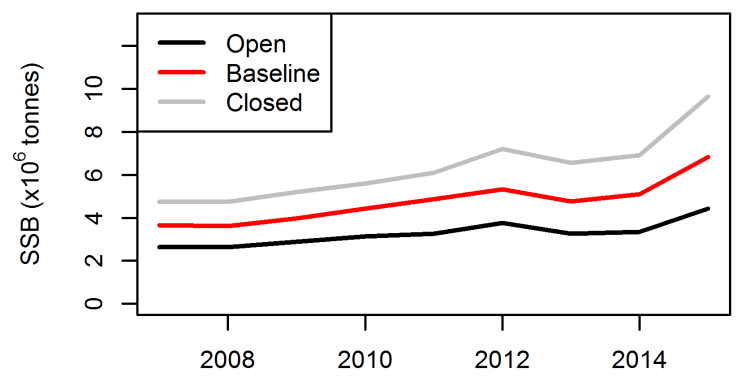

c) average adult length dists.

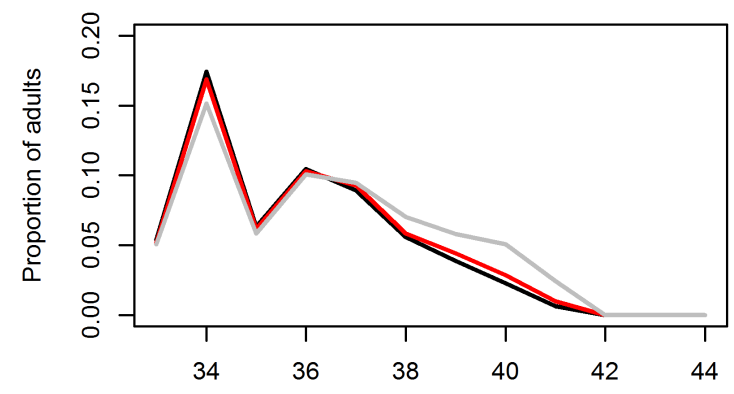

e) map showing division $4 a$

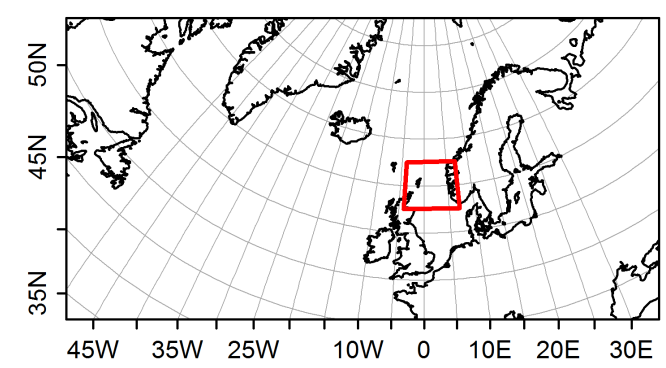

b) average recruitment

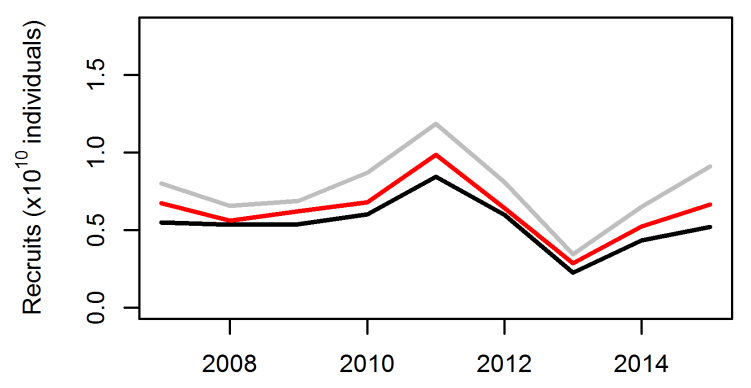

d) Proportion in 4a

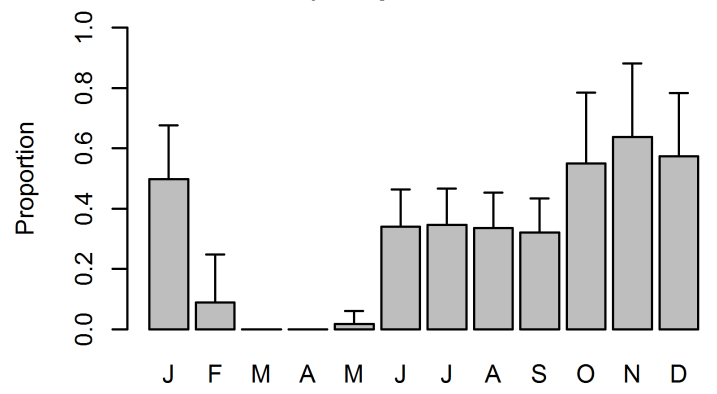

Figure 5. Simulated a) SSB, b) recruitment and c) length distributions of large ( $\geq 33 \mathrm{~cm})$ fish, all on February $1^{\text {st }}$, when ICES division 4 a was open to fishing year round (open), open to fishing only from Feb $15^{\text {th }}$ to Sep $1^{\text {st }}$ (baseline) and closed year round (closed). Predictions are averaged over five simulations in each scenario. Panel d) shows the mean proportion of the population in division $4 \mathrm{a}$ in each month of the year, averaged over 15 simulations, with error bars showing standard deviations. Panel e) shows the location of division $4 a$.

\section{Discussion}

We have developed, calibrated and evaluated a generic IBM which relates fish population dynamics and structure to spatial and temporal variation in food availability, temperature and exploitation. Key features of the model are that it (1) includes a realistic energy budget; (2) includes the full life cycle; (3) is spatially-explicit and (4) incorporates satellite remote-sensing (RS) data to represent the environmental drivers. To demonstrate the use of the model we calibrated it for mackerel in the North East Atlantic and showed it successfully matches the available data on population dynamics (Fig. 3) and population structure (Fig. 4). We then showed the model's ability to test the population consequences of simple hypothetical management scenarios (Fig. 5).

Model fits to the data on mackerel population structure (Fig. 4) give insight into how well different aspects of the energy budget are represented. For example, we consider growth in length to be reasonable because individuals reach sexual maturity at about the right age (Fig. 4a), which is determined by length, and because the modes of the length distribution of different cohorts match 
well at two different times of year (Figs. 4 e and f). However, there is less variability in the predicted length of individuals in a cohort than in the data. One reason could be that each cohort in the model is represented by a small number (ten) of super-individuals, chosen for computational reasons. We consider growth in mass to be reasonable because predicted weight-at-age in summer matches the data well (Fig. 4c). Storage of lipid when feeding in summer is reflected in increased weight-at-length and is supported by the good model fit to data on the monthly variation in the weight of $36 \mathrm{~cm}$ individuals (Fig. 4d). Lastly, total mortality is reasonable because the adult age distribution in summer is matched well (Fig. 4b). The model also fits data on the mackerel population dynamics that were used for calibration well (Fig. 3). However, it is because they were not used for calibration that we consider the data on population structure to support our energy budget structure.

The main advantage of the IBM approach is that it provides a single framework that can explicitly incorporate food web interactions, environmental drivers, density dependence and spatial structuring. This allows the model to capture two key processes that affect recruitment in many species. Firstly, the model captures the generally-accepted "growth-mortality hypothesis" (Anderson, 1988; McGurk, 1986; Ware, 1975). Larval and juvenile background mortality decreases with body size. As a result, cumulative survival in a cohort depends on its growth rate, and hence food availability, temperature and the density of competitors. The predator-prey size ratio also dictates that individuals become less vulnerable to explicit predation with increasing size. Secondly, the model captures the effects of parental condition on spawning success, which has been shown for many taxa (Mcbride et al., 2015). The initial abundance of a cohort (i.e. the number of eggs initially) depends on the amount of energy the spawning stock is able to accumulate before spawning. This depends on the history of food availability, temperature and density of competitors when adults were last feeding (see TRACE section 8 for more details). In sum, recruitment in the model emerges from parental condition and early survival. Predictions are process-based and should be less vulnerable to the problems of extrapolation than those obtained from standard stock-recruitment curves.

We hope the model will be used to explore the effects of multiple ecosystem drivers in future. We have demonstrated its ability to test the population consequences of management scenarios by simulating hypothetical fishery closures in one sector of the North Sea. These simple scenarios produced expected population responses (Fig. 5), but highlight how it may be applied going forward. This feature is in demand because spatial management in fisheries is increasingly prevalent (Halpern et al., 2012), whether as no-take zones like marine protected areas, or more nuanced measures such as spatially-explicit quotas (Rassweiler et al., 2012). Alongside the effects of fishing, the model could also be used to explore the effects of climate change. This may involve coupling the model to lower trophic level biogeochemical and hydrodynamics models, which can provide various forcing variables under climate change scenarios. One particular application could be to investigate change in fish distribution in response to increasing in SST, and its implications to management.

Although we parameterised the model for mackerel in the North East Atlantic, it should be applicable to other species and locations. This is because: (1) the energy budget is based on fundamental principles of behavioural and physiological ecology and incorporates generic laws for the scaling of energy uptake and expenditure with body mass and temperature (Sibly et al., 2013); (2) it captures key processes that relate the environmental drivers to the population structure and dynamics of many species, such as the effects of parental condition and early survival on recruitment; and (3) the RS data is freely-available and has global coverage. Although RS-based estimates of SST and chlorophyll come with a certain level of uncertainty associated with the satellite retrievals, the level of these random errors are generally bounded (often $<30 \%, \mathrm{GCOS}$ 2011)). Moreover, with the continuous improvement of the quality of satellite data, the error propagation through the model arising from the model inputs will be greatly reduced. As such we hope that the model location and extent can be changed to utilize the satellite data matching the distribution of the chosen species, and that it will be mainly the values of the parameters that will 
need to be changed for different species, many of which can be found at FishBase. The model should also be able to accommodate multiple species, because interactions can occur via density dependent effects on ingestion, or by explicit size-based predation. Unlike previous generic marine fish IBMs, e.g., OSMOSE (Shin and Cury, 2004, 2001), our model includes bioenergetics, and we hope it will provide a step towards broadly applicable bioenergetics IBMs.

The main caveat of our generic approach is that fish populations exhibit a wide range of spatial patterns that vary over their ontogeny and thus it is not possible to provide a generic movement sub-model. Users will need to devise algorithms appropriate to the species being modelled. In this study we approximated spawning, feeding, overwintering and nursery areas geographically from various sources. We were able to further delineate these areas by environmental features, such as SST and depth, using information on S. scombrus from the literature. However, in the current model formulation, movement within each habitat type follows a random walk, and migration triggers are hard-wired. One goal of future work should be to develop a more realistic movement model. For example, the approach of Politikos et al. (2015) could be followed, using survey data on the spatial distribution of a species to construct environmentally-driven movement algorithms. Moreover, the delineation of different habitat types could be informed by habitat suitability modelling (e.g. Brunel et al., 2017; Morris and Ball, 2006). In this way a population's spatial distribution can become an emergent feature of the model just as its population dynamics are now.

IBMs can play an important role in conservation planning and wildlife management (McLane et al., 2011), and we hope that this work will benefit the fisheries management community. IBMs represent a single framework in which food-web interactions, density dependence, spatial structuring and the wider environment can be incorporated, thus being consistent with the ecosystems approach to fisheries management. The effects of these drivers on fish populations typically arise from their effects on the constituent individuals (Ward et al., 2016). Explicit incorporation of these drivers makes IBMs an improvement on age/size structured models. The basis for our model is a realistic energy budget, which represents a mechanistic framework by which the ecosystem drivers affect the characteristics of the individuals. Population measures are then calculated as the sum of these characteristics. This means that predictions of population-level processes such as recruitment emerge rather than being parameterised. Going forward our model can be used to address several strategic management questions, including the population consequences of different management and environmental scenarios.

\section{Acknowledgements}

We would like to thank Elske van der Vaart for her help with the $A B C$ analysis, Piera Carpi for her advice on possible management scenarios, Steve Mackinson for general advice on mackerel, Vicky Boult for reviewing the model code and two anonymous reviewers for their constructive comments on the manuscript. We also acknowledge NASA's Ocean Biology Processing Group for providing the satellite remote sensing data, and the National Oceanographic Data Centre for providing the bathymetric data. This work was supported by a NERC PhD studentship [grant number NE/L002566/1] with CASE sponsorship from CEFAS.

\section{Author's contributions}

$\mathrm{SR}, \mathrm{RS}, \mathrm{RT}$ and $\mathrm{KH}$ acquired funding for the project. All authors contributed the conception of the paper and design of the methodology. RB, RS and SR led the writing of the manuscript. All authors contributed critically to the drafts and gave final approval for publication.

\section{References}

Anderson, J.T., 1988. A Review of Size Dependent Survival During Pre-Recruit Stages of Fishes in Relation to Recruitment. J. Northw. All. Fish. SCl 8, 55-66.

Augusiak, J., Van den Brink, P.J., Grimm, V., 2014. Merging validation and evaluation of ecological 
models to "evaludation": A review of terminology and a practical approach. Ecol. Modell. 280, 117-128. doi:10.1016/j.ecolmodel.2013.11.009

Bartsch, J., Coombs, S.H., 2004. An individual-based model of the early life history of mackerel (Scomber scombrus) in the eastern North Atlantic, simulating transport, growth and mortality. Fish. Oceanogr. 13, 365-379. doi:10.1111/j.1365-2419.2004.00305.x

Beddington, J.R., 1975. Mutual interference between parasites or predators and its effect on searching efficiency. J. Anim. Ecol. 44, 331-340. doi:10.2307/3866

Borja, A., Uriarte, A., Egaña, J., 2002. Environmental factors and recruitment of mackerel, Scomber scombrus L. 1758, along the north-east Atlantic coasts of Europe. Fish. Oceanogr. 11, 116-127. doi:10.1046/j.1365-2419.2002.00190.x

Brodziak, J., lanelli, J., Lorenzen, K., Methot, R.D., 2011. Estimating Natural Mortality in Stock Assessment Applications. U.S. Dep. Commer., NOAA Tech. Memo. NMFS-F/SPO-119, 38 p. 38.

Brunel, T., van Damme, C.J.G., Samson, M., Dickey-Collas, M., 2017. Quantifying the influence of geography and environment on the northeast Atlantic mackerel spawning distribution. Fish. Oceanogr. 1-15. doi:10.1111/fog.12242

Cadrin, S., Dicky-Collas, M., 2013. Stock assessment methods for sustainable fisheries. ICES J. Mar. Sci. 72, 1-6. doi:10.1093/icesjms/fsu228

Clarke, A., Johnston, N.M., 1999. Scaling of metabolic rate with body mass and temperature in teleost fish. J. Anim. Ecol. 68, 893-905. doi:10.1046/j.1365-2656.1999.00337.x

DeAngelis, D.L., Goldstein, R. a., O'Neill, R. V., 1975. A Model for Tropic Interaction. Ecology 56, 881892. doi:10.2307/1936298

DeAngelis, D.L., Grimm, V., 2014. Individual-based models in ecology after four decades. F1000 Prime Reports 6, 39. doi:10.12703/P6-39

Fortier, L., Villeneuve, A., 1996. Cannibalism and predation on fish larvae by larvae of Atlantic mackerel, Scomber scombrus: Trophodynamics and potential impact on recruitment. Fish. Bull. 94, 268-281.

Fry, F.E.J., 1971. Effect of environmental factors on the physiology of fishes. Yale J. Biol. Med. 30, 152-153. doi:10.1016/S0044-8486(97)82982-1

Fulton, E.A., Fuller, M., Smith, A.D.M., Punt, A.E., 2004. Ecological indicators of the ecosystem effects of fishing: final report. Aust. Fish. Manag. Auth. Rep. 99, 116. doi:10.1017/СBO9781107415324.004

Garcia, S.M., Cochrane, K.L., 2005. Ecosystem approach to fisheries: A review of implementation guidelines. ICES J. Mar. Sci. 62, 311-318. doi:10.1016/j.icesjms.2004.12.003

GCOS, 2011. Systematic Observation Requirements For Satellite-Based Data Products for Climate 2011 Update.

Gluyas-Millan, M.G., Castonguay, M., Quinonez-Velazouez, C., 1998. Growth of juvenile Pacific mackerel, Scomber japonicus in the Gulf of California. Sci. Mar. 62, 225-231.

Goldman, K., 2005. Age and growth of elasmobranch fishes, in: Musick, J., Bonfil, R. (Eds.), Management Techniques for Elasmobranch Fisheries. p. 93.

Grimm, V., Augusiak, J., Focks, A., Frank, B.M., Gabsi, F., Johnston, A.S.A., Liu, C., Martin, B.T., Meli, M., Radchuk, V., Thorbek, P., Railsback, S.F., 2014. Towards better modelling and decision 
support: Documenting model development, testing, and analysis using TRACE. Ecol. Modell. 280, 129-139. doi:10.1016/j.ecolmodel.2014.01.018

Grimm, V., Berger, U., Bastiansen, F., Eliassen, S., Ginot, V., Giske, J., Goss-Custard, J., Grand, T., Heinz, S.K., Huse, G., Huth, A., Jepsen, J.U., Jørgensen, C., Mooij, W.M., Müller, B., Pe'er, G., Piou, C., Railsback, S.F., Robbins, A.M., Robbins, M.M., Rossmanith, E., Rüger, N., Strand, E., Souissi, S., Stillman, R. a., Vabø, R., Visser, U., DeAngelis, D.L., 2006. A standard protocol for describing individual-based and agent-based models. Ecol. Modell. 198, 115-126. doi:10.1016/j.ecolmodel.2006.04.023

Grimm, V., Berger, U., DeAngelis, D.L., Polhill, J.G., Giske, J., Railsback, S.F., 2010. The ODD protocol: A review and first update. Ecol. Modell. 221, 2760-2768. doi:10.1016/j.ecolmodel.2010.08.019

Grimm, V., Revilla, E., Berger, U., Jeltsch, F., Mooij, W.M., Steven, F., Thulke, H., Weiner, J., Wiegand, T., Deangelis, D.L., Railsback, S.F., 2005. Pattern-Oriented Modeling of Agent Based Complex Systems: Lessons from Ecology. Am. Assoc. Adv. Sci. 310, 987-991. doi:10.1126/science.1116681

Hall, S.J., Collie, J.S., Duplisea, D.E., Jennings, S., Bravington, M., Link, J., 2006. A length-based multispecies model for evaluating community responses to fishing. Can. J. Fish. Aquat. Sci. 63, 1344-1359. doi:10.1139/f06-039

Halpern, B.S., Diamond, J., Gaines, S., Gelcich, S., Gleason, M., Jennings, S., Lester, S., Mace, A., McCook, L., McLeod, K., Napoli, N., Rawson, K., Rice, J., Rosenberg, A., Ruckelshaus, M., Saier, B., Sandifer, P., Scholz, A., Zivian, A., 2012. Near-term priorities for the science, policy and practice of Coastal and Marine Spatial Planning (CMSP). Mar. Policy 36, 198-205. doi:10.1016/j.marpol.2011.05.004

Hilborn, R., Walters, C., 1992. Quantitative fisheries stock assessment: Choice, dynamics and uncertainty.

ICES, 2017. SWC-IBTS Data (DATRAS).

ICES, 2014a. Manual for the mackerel and horse mackerel egg surveys (MEGS): sampling at sea., Series of ICES Survey Protocols.

ICES, 2014b. Report of the Report of the Working Group on Widely Distributed Stocks (WGWIDE) report 2014 37-192.

ICES, 2008. ICES WGWIDE REPORT 2008 Report of the Working Group on Widely Distributed Stocks (WGWIDE) 702.

Jansen, T., Burns, F., 2015. Density dependent growth changes through juvenile and early adult life of North East Atlantic Mackerel (Scomber scombrus). Fish. Res. 169, 37-44. doi:10.1016/j.fishres.2015.04.011

Jansen, T., Kristensen, K., Kooij, J. Van Der, Post, S., Campbell, A., Utne, K.R., Carrera, P., Jacobsen, J.A., Gudmundssdottir, A., Roel, B.A., Hatfield, E.M.C., 2014. Nursery areas and recruitment variation of Northeast Atlantic mackerel (Scomber scombrus). ICES J. Mar. Sci. doi:10.1093/icesjms/fsu186

Kaplan, I.C., Gray, I.A., Levin, P.S., 2013. Cumulative impacts of fisheries in the California Current. Fish Fish. 14, 515-527. doi:10.1111/j.1467-2979.2012.00484.x

Kooijman, S.A.L.M., Metz, J.A.J., 1983. On the dynamics of chemically stressed populations: The deduction of population consequences from effects on individuals. Hydrobiol. Bull. 17, 88-89. doi:10.1007/BF02255198 
Lett, C., Rose, K. a, Megrey, B. a, 2009. Biophysical models of small pelagic fish, in: Climate Change and Small Pelagic Fish. Cambridge University press, pp. 1-64.

Martin, B.T., Heintz, R., Danner, E.M., Nisbet, R.M., 2017. Integrating lipid storage into general representations of fish energetics. J. Anim. Ecol. 86, 812-825. doi:10.1111/1365-2656.12667

Mcbride, R.S., Somarakis, S., Fitzhugh, G.R., Albert, A., Yaragina, N. a., Wuenschel, M.J., AlonsoFernández, A., Basilone, G., 2015. Energy acquisition and allocation to egg production in relation to fish reproductive strategies. Fish Fish. 16, 23-57. doi:10.1111/faf.12043

McGurk, M.D., 1986. Natural mortality of marine pelagic fish eggs and larvae: role of spatial patchiness. Mar. Ecol. Prog. Ser. 34, 227-242. doi:10.3354/meps034227

McLane, A.J., Semeniuk, C., McDermid, G.J., Marceau, D.J., 2011. The role of agent-based models in wildlife ecology and management. Ecol. Modell. 222, 1544-1556. doi:10.1016/j.ecolmodel.2011.01.020

Morris, L., Ball, D., 2006. Habitat suitability modelling of economically important fish species with commercial fisheries data. ICES J. Mar. Sci. 63, 1590-1603. doi:10.1016/j.icesjms.2006.06.008

NASA OBPG, 2017a. Moderate-resolution Imaging Spectroradiometer (MODIS) Aqua Chlorophyll-a OCI Algorithm Data; 2014 Reprocessing. doi:10.5067/AQUA/MODIS/L3M/CHL/2014

NASA OBPG, 2017b. Moderate-resolution Imaging Spectroradiometer (MODIS) Aqua Sea Surface Temperature (daytime) Data; 2014 reprocessing. doi:10.5067/AQUA/MODIS_OC.2014.0

Nøttestad, L., Anthonypillai, V., Tangen, Ø., Høines, Å., Utne, K.R., Óskarsson, G.J., Ólafsdóttir, a., Jónsson, S., Jacobsen, J. a, Smith, L., Jansen, T., Post, S., 2016. Cruise report from the International Ecosystem Summer Survey in the Nordic Seas (IESSNS) with M/V "M. Ytterstad", M/V “Vendla", M/V "Tróndur í Gøtu”, M/V “Finnur Fríði” and R/V “Árni Friðriksson”, 1 - 31 July 2016. Ices C. 2016/Acom16/Wd1 1-41.

Nottestad, L., Diaz, J., Pena, H., Sioland, H., Huse, G., Ferno, A., 2016. Feeding strategy of mackerel in the Norwegian Sea relative to currents, temperature, and prey. ICES J. Mar. Sci. 73, 1127-1137. doi:10.1093/icesjms/fst048

Nøttestad, L., Jo, S.P., Jacobsen, J.A., Utne, K.R., Guðmundur, J.O., Tangen, Ø., Anthonypillai, V., Aanes, S., Vølstad, J.H., Bernasconi, M., Holst, J.C., Jansen, T., Slotte, A., Debes, H., Smith, L., Sveinbjo, S., 2015. Quantifying changes in abundance, biomass and spatial distribution of Northeast Atlantic mackerel in the Nordic seas from 2007 to 2014. ICES J. Mar. Sci. 73, 359373. doi:10.1093/icesjms/fsv218

Olafsdottir, A., Slotte, A., Arge Jacobsen, J., Gudmundur, J., Oskarssn, G., Utne, K., Nottestad, L., 2016. Changes in weight-at-length and size-at-age of mature Northeast Atlantic mackerel from 1984:2013: effects of mackerel stock size and herring stock size 69, 682-693. doi:10.1093/icesjms/fst048

Pepin, P., 1991. Effect of temperature and size on development, mortality and survival rates of the pelagic early life history satges of marine fish. Can. J. Fish. Aquat. Sci. 48, 503-518. doi:10.1139/f91-065

Peters, R., 1983. Ecological implications of body size. Cambridge University Press, New York.

Pethybridge, H., Roos, D., Loizeau, V., Pecquerie, L., Bacher, C., 2013. Responses of European anchovy vital rates and population growth to environmental fluctuations: An individual-based modeling approach. Ecol. Modell. 250, 370-383. doi:10.1016/j.ecolmodel.2012.11.017

Petitgas, P., Uriarte, A., Nogueira, E., Massé, J., Cotano, U., 2010. Life-cycle spatial patterns of small 
pelagic fish in the Northeast Atlantic. ICES Coop. Res. Rep. 306, 40-44.

Politikos, D., Huret, M., Petitgas, P., 2015. A coupled movement and bioenergetics model to explore the spawning migration of anchovy in the Bay of Biscay. Ecol. Modell. 313, 212-222. doi:10.1016/j.ecolmodel.2015.06.036

Politikos, D., Somarakis, S., Tsiaras, K., Giannoulaki, M., Petihakis, G., Machias, A., Triantafyllou, G., 2015. Simulating anchovy's full life cycle in the northern Aegean Sea (eastern Mediterranean): A coupled hydro-biogeochemical-IBM model. Prog. Oceanogr. 138, 399-416. doi:10.1016/j.pocean.2014.09.002

Polovina, J.J., 1984. Model of a coral reef ecosystem. Coral Reefs 3, 1-11. doi:10.1007/BF00306135

Rassweiler, a., Costello, C., Siegel, D. a., 2012. Marine protected areas and the value of spatially optimized fishery management. Proc. Natl. Acad. Sci. 109, 11884-11889. doi:10.1073/pnas.1116193109

Rose, K.A., Cowan, J.H., Clark, M.E., Houde, E.D., Wang, S. Bin, 1999. An individual-based model of bay anchovy population dynamics in the mesohaline region of Chesapeake Bay. Mar. Ecol. Prog. Ser. 185, 113-132. doi:10.3354/meps185113

Sambilay Jr, V., 1990. Interrelationships between swimming speed, caudal fin aspect ratio and body length of fishes. Fishbyte.

Scheffer, M., Baveco, J.M., Deangelis, D.L., Rose, K. a, Vannes, E.H., 1995. Super-Individuals A Simple Solution For Modeling Large Populations On An Individual Basis. Ecol. Modell. 80, 161-170. doi:10.1016/0304-3800(94)00055-M

Schmolke, A., Thorbek, P., DeAngelis, D.L., Grimm, V., 2010. Ecological models supporting environmental decision making: A strategy for the future. Trends Ecol. Evol. 25, 479-486. doi:10.1016/j.tree.2010.05.001

Sette, O., 1943. Part I. Biology of the atlantic mackerel (Scomber scombrus) of North America. Fish. Bull. 50.

Shin, Y.-J., Cury, P., 2004. Using an individual-based model of fish assemblages to study the response of size spectra to changes in fishing. Can. J. Fish. Aquat. Sci. 61, 414-431. doi:10.1139/f03-154

Shin, Y.J., Cury, P., 2001. Exploring fish community dynamics through size-dependent trophic interactions using a spatialized individual-based model. Aquat. Living Resour. 14, 65-80. doi:Doi 10.1016/S0990-7440(01)01106-8

Sibly, R.M., Grimm, V., Martin, B.T., Johnston, A.S. a, Kulakowska, K., Topping, C.J., Calow, P., NabeNielsen, J., Thorbek, P., Deangelis, D.L., 2013. Representing the acquisition and use of energy by individuals in agent-based models of animal populations. Methods Ecol. Evol. 4, 151-161. doi:10.1111/2041-210x.12002

Sirnard, P., Castonguay, M., Arnours, D.D., Magnan, P., 1992. Growth comparison between juvenile Atlantic mackerel from the two pawning groups of the Northwest Atlantic. Can. J. Fish. Aquat. Sci. 49.

Skern-Mauritzen, M., Ottersen, G., Handegard, N.O., Huse, G., Dingsør, G.E., Stenseth, N.C., Kjesbu, O.S., 2015. Ecosystem processes are rarely included in tactical fisheries management. Fish Fish. 165-175. doi:10.1111/faf.12111

Thorpe, R.B., Dolder, P.J., Reeves, S., Robinson, P., Jennings, S., 2016. Assessing fishery and ecological consequences of alternate management options for multispecies fisheries. ICES J. Mar. Sci. J. du Cons. fsw028. doi:10.1093/icesjms/fsw028 
Travers, M., Watermeyer, K., Shannon, L.J., Shin, Y.J., 2010. Changes in food web structure under scenarios of overfishing in the southern Benguela: Comparison of the Ecosim and OSMOSE modelling approaches. J. Mar. Syst. 79, 101-111. doi:10.1016/j.jmarsys.2009.07.005

van der Vaart, E., Beaumont, M. a., Johnston, A.S. a., Sibly, R.M., 2015. Calibration and evaluation of individual-based models using Approximate Bayesian Computation. Ecol. Modell. 312, 182190. doi:10.1016/j.ecolmodel.2015.05.020

van der Vaart, E., Johnston, A.S.A., Sibly, R.M., 2016. Predicting how many animals will be where: How to build, calibrate and evaluate individual-based models. Ecol. Modell. 326, 113-123. doi:10.1016/j.ecolmodel.2015.08.012

Villamor, B., Gonzalez-Pola, C., Lavín, a., Valdés, L., Lago De Lanzós, a., Franco, C., Cabanas, J.M., Bernal, M., Hernandez, C., Iglesias, M., Carrera, P., Porteiro, C., 2011. Environmental control of Northeast Atlantic mackerel (Scomber scombrus) recruitment in the southern Bay of Biscay: Case study of failure in the year 2000. Fish. Oceanogr. 20, 397-414. doi:10.1111/j.13652419.2011.00592.x

von Bertalanffy, L., 1938. A quantitative theory of organic growth. Hum. Biol. 10, 181-213.

Ward, T.D., Algera, D.A., Gallagher, A.J., Hawkins, E., Horodysky, A., Jørgensen, C., Killen, S.S., McKenzie, D.J., Metcalfe, J.D., Peck, M.A., Vu, M., Cooke, S.J., 2016. Themed Issue Article : Conservation Physiology of Marine Fishes Understanding the individual to implement the ecosystem approach to fisheries management. Conserv. Physiol. 4, 10.1093/conphys/cow005. doi:10.1093/conphys/cow005.

Ware, D.M., 1975. Relation between egg size, growth, and natural mortality of larval fish. J. Fish. Res. Board Canada 32, 2503-2512. doi:10.1139/f75-288 